\title{
Absence of HTLV-I and HTLV-II Proviral Genome in the Brains of Patients with Multiple Sclerosis and Amyotrophic Lateral Sclerosis
}

\author{
G.A. Dekaban, A.J. Hudson and G.P.A. Rice
}

\begin{abstract}
Previous studies have failed to provide serological evidence to incriminate a retroviral infection in the cause of multiple sclerosis. Gene amplification techniques have also failed to identify retroviral footprints in DNA from peripheral blood leukocytes. Here we provide evidence that proviral DNA of HTLV-I and HTLV-II is not found in the central nervous system tissues of patients with multiple sclerosis, patients with amyotrophic lateral sclerosis and controls.
\end{abstract}

RÉSUMÉ: Absence du génome proviral du HTLV-1 et du HTLV-2 dans le cerveau de patients atteints de sclérose en plaques et de sclérose latérale amyotrophique. Des études antérieures n'ont pas montré de manifestations sérologiques impliquant une infection rétrovirale comme cause de la sclérose en plaques. Les techniques d'amplification génique n'ont pas identifié d'empreinte rétrovirale dans l'ADN de leukocytes du sang périphérique. Dans cet article, nous démontrons que l'ADN proviral de HTLV-1 et de HTLV-2 ne se retrouve pas dans les tissues du système nerveux central de patients atteints de sclérose en plaques, de sclérose latérale amyotrophique et de contrôles.

Can. J. Neurol. Sci. 1992; 19: 458-461

In the last decade, retroviruses have been incriminated in the pathogenesis of some major diseases of the nervous system. The encephalopathy caused by HIV-1 and the myelopathy caused by HTLV-I are prime examples. The first attempts to implicate such agents in MS provided some encouraging hope that retroviruses might be involved, although the pilot observations have not been reproducible (reviewed 1 ). Some murine models of amyotrophic lateral sclerosis (ALS) have been shown to be caused by a retrovirus which causes a noninflammatory destruction of anterior horn cells. ${ }^{2}$ These models have raised speculation that a human retrovirus could act similarly in the pathogenesis of ALS.

We have been unable to find any serological evidence for a human retroviral infection in the pathogenesis of multiple sclerosis (MS) or amyotrophic lateral sclerosis (ALS).' With enzyme linked immunoassays or western blot techniques we could not find antibody to HTLV-1 or HIV-1 in patients with MS or ALS. Furthermore, with gene amplification techniques, we were unable to identify unique retroviral sequences in DNA harvested from blood leukocytes. ${ }^{2}$

It was important to extend these observations for several reasons. In other nervous system diseases, retroviral footprints can be found only at the site of tissue injury. For example, we found that in a patient with the myelopathy associated with HTLV-I infection, viral genes could be amplified only from pathologically abnormal spinal cord, and not from elsewhere in the neuraxis. ${ }^{4}$ It has also become apparent that serology is not uniformly positive in patients with AIDS, ${ }^{5}$ nor in patients with myelopathies caused by HTLV-1. ${ }^{6}$ A retroviral etiology in these cases has been shown by gene amplification.

We extended our studies to include DNA extracted from brain and spinal cord. We were unable to find retroviral sequences specific to HTLV-I, HTLV-II or HIV in the brains and spinal cords of patients with MS, ALS and a number of patients with other nervous system diseases.

\section{Materials and Methods}

\section{Cell Lines}

The HTLV-II infected Mo B-cell line was obtained from the American Tissue Culture Collection and grown in Iscove's modified Dulbecco's medium, supplemented with glutamine, $2.5 \mathrm{mM}$ Hepes, $10 \%$ fetal calf serum, penicillin and streptomycin.

From the Department of Clinical Neurological Sciences, University of Western Ontario, London

Received December 18, 1991. Accepted in final form May 14, 1992.

Reprint requests to: Dr. G.P.A. Rice, INS Department, University Hospital, 339 Windermere Road, London, Ontario, Canada N6A 5A5 


\section{Source of Neural Tissues}

Brains and spinal cords were removed from patients with clinically definite ALS and MS within 24 hours of death. The patients with MS had been followed in the London Regional Multiple Sclerosis Clinic, and the ALS patients were obtained from the Southwestern Ontario ALS Registry. Control material was obtained from patients who had succumbed to GuillainBarre syndrome, various malignancies or fulminant liver failure.

In the patients with ALS $(n=5)$ DNA was extracted from frontal and occipital cortex, centrum semiovale and medulla oblongata. The hypoglossal nucleus had been involved clinically in all of these patients and this tissue was included in the sampling. In patients with MS $(n=5)$ we sampled both plaque and the area surrounding plaques, in addition to the above mentioned areas. At least one plaque and one periplaque region was sampled in each MS patient. DNA extracted from peripheral blood lymphocytes from an individual known to have a myelopathy caused by HTLV-I served as a positive control (fresh, or frozen tissues were unavailable).

\section{Purification of DNA}

The method for DNA extraction has been described previously. ${ }^{3}$ We performed a sham extraction each time that brain DNA was extracted. In this control, the entire extraction procedure is performed, except for the inclusion of sample DNA. This excludes the possibility of DNA contamination during the extraction procedure.

We also ensured that all DNA extracted was suitable for amplification by testing the ability of DNA to amplify beta-actin primers. Any samples that failed to amplify with the beta-actin primers were further purified by a second extraction with phenol/chloroform or by passage over genomic DNA isolation columns (ASAP, Boehringer Mannheim).

\section{Gene Amplification}

We routinely employed the controls outlined by Kwok and Higuchi.?
The primers for HTLV-1 gag p24 and pol have been described previously. ${ }^{3.7}$ The HTLV-II pol primers and probe were synthesized based upon sequence information at the following nucleotide positions: 5 ' primer - 3824 to 3851 , 3' primer - 4280 to 4300 ; probe -4190 to 4217 , based on published sequence. ${ }^{9}$ The HTLV-II en ' primers and probe were constructed as follows: 5' primer - 5602 to $5624 ; 3$ ' primer - 6020 to 6040 , probe -5912 to 5934 . The beta-actin primers were constructed as follows: 5' primer - 1857-1883, 3' primer - 2252 to 2277 , all based on published sequence. ${ }^{3}$

Oligonucleotides were synthesized on an ABI oligonucleotide synthesizer and purified as described previously. ${ }^{3.4}$ TaqI DNA polymerase was obtained from Perkin Elmer-Cetus or Promega Biotec. Both gave equivalent results. All amplifications were carried out using the "hot start" approach in which the reactions were brought $1080^{\circ} \mathrm{C}$ before Taq I polymerase was added. All samples were initially denatured for 4 minutes by heating at $95^{\circ} \mathrm{C}$ and then amplified for 30 cycles of denaturation at $95^{\circ} \mathrm{C}$ for 70 seconds, annealing at $55^{\circ} \mathrm{C}$ for 30 seconds and elongation at $72^{\circ} \mathrm{C}$ for 90 seconds. After the last cycle a final extension was carried out for 10 minutes at $72^{\circ} \mathrm{C}$. The PCR products were analyzed as previously described by agarose electrophoresis and southern blotting. ${ }^{3}$

\section{Results}

We first ascertained that all of the DNA extracted could support the amplification of a cellular housekeeping gene. All of the specimens yielded the expected oligonucleotide fragment with the beta-actin primers. Further we showed that with the sham control there was no introduction of exogenous contaminating sequences, and with the primer control there was no amplification of the priming reagents alone (data not shown).

We then amplified the DNA extracted from the clinical samples for evidence of p24 sequences from the HTLV-I gag gene. We could uniformly demonstrate the appropriate .623 kilobase fragment in the HLTV-1 infected control. This band was

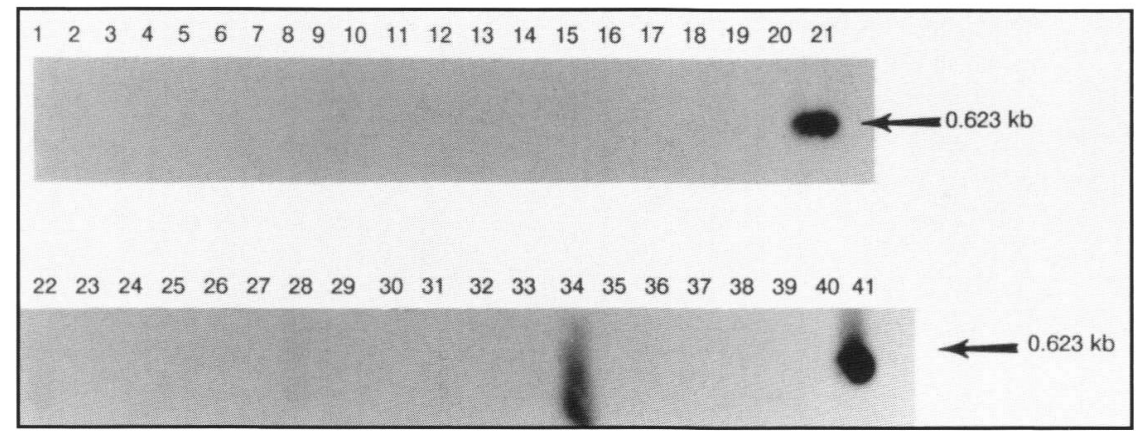

Figure I - Amplification of HTLV-I gag p24 sequences from a representative selection of DNA samples extracted from brains of controls (lanes 1-8), a patient with Guillain-Barre Syndrome (lanes 9-12), patients with MS (lanes 12-26, lane 2I excepted) and patients with ALS (lanes 27-39). Sham DNA extraction controls for samples that precede them are located in lanes $2,5,8,12,14,16,19,23,26,32,35$ and 39. The HTLV-I positive DNA sample extracted from peripheral blood of a patient with HAM/TSP is in lane 21 and 41 . Lane 40 contains the water control. Lanes 4.7, 9,28,31.34 and 38 contain DNA from frontal grey matter: Lanes 3, 6, and 29 contain DNA from the occipital grey matter: Lanes $I$ and il contain DNA from the frontal white matter. Lane 36 contains DNA from medulla. Lanes 13.17.20 and 24 contain DNA from MS plaque areas and lanes 15.18.22 and 25 contain DNA from MS peri-plaque areas. The streak of radioactive signal between lanes 33 and 34 is a hybridization artifact. 


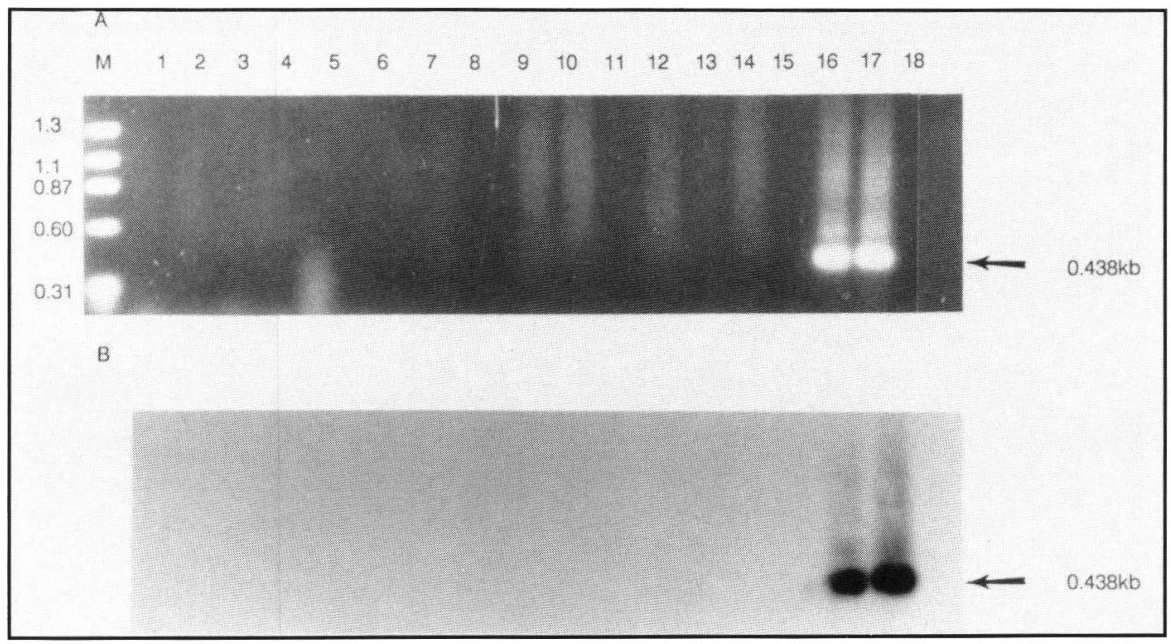

Figure 2 - Amplification of HTLV-II envelope 438 bp sequence from a representative selection of DNA sample extracted from controls (lane 1-4) and patients with ALS (lanes 5-15). The HTLV-II positive DNA samples and a $10^{-1}$ dilution are located in lanes 17 and 16 , respective1y. The water control is located in lane 18. Sham DNA extractions for samples that precede them are located in lanes 4.10 and 13. Lanes 1, 6.9,12 and 16 contain DNA from frontal grey matter: Lanes 2, 5,8.11 and 15 contain DNA from motor strip grey matter: Lanes 3 and 7 contain DNA from occipal grey matter. Lane 14 contains DNA from medulla. Panel A. ethidium bromide stained agarose gel and Panel B is the corresponding southern blot.

uniformly absent in the negative controls and in all of the clinical materials that we studied (Figure 1). Similar results were obtained in the pol primers (not shown).

We also examined the same DNA samples for presence of the HTLV-II env and pol genes. These did not have any known homology with HTLV-I. As shown in Figure 2, we could not amplify HTLV-II env sequences. Similar negative results were obtained for the HTLV-II pol primers.

\section{Discussion}

Evidence to implicate a retrovirus in the etiology of multiple sclerosis has not been forthcoming. Although some of the first serological and gene amplification reports suggested a role for a virus similar to $\mathrm{HTLV}_{-} \mathrm{I}^{10}$ the consensus is that these observations are not reproducible. ${ }^{11-15}$

The failure to identify retroviral genes in the tissues of ALS patients is in keeping with the negative serological studies published to date.' A virus etiology for ALS is still possible. The most compelling evidence derives from the animal models. The mechanism of anterior cell destruction is complicated in these models, with important virus- and host-determined restricting elements.

The failure to amplify highly conserved sequences from HTLV-I and HTLV-II retroviruses certainly does not eliminate the possibility of some role for a retroviral infection. If a retrovirus is involved, it likely derives from a different family. The experiments described in this report were designed to be highly specific for HTLV-I and II sequences. The conditions would not permit the detection of more distantly related retroviruses. Dropping the stringency would possibly permit the detection of other exogenous retroviral sequences, but would be complicated by false positive detection of partially homologous sequences of endogenous retrovirus or cellular sequences.

\section{ACKNOWLEDGEMENTS}

GD and GPAR are recipients of Career Development Awards from the Ministry of Health of Ontario. We are grateful for the technical expertise of Elaine King and secretarial assistance of Donna Greer. This research was supported by both the Multiple Sclerosis and Amyotrophic Lateral Sclerosis Societies of Canada.

\section{REFERENCES}

1. Weinshenker BG, Dekaban GA, Waters D, Bess J, Arthur L, Rice GPA. Retroviruses and multiple sclerosis: I. Analysis of seroreactivity by western blot and radioimmune essay. Neurology 1990; 40(8): 1251-1253.

2. Oldstone MBA, Lampert PW, Lee S, et al. Pathogenesis of the slow disease of the central nervous system associated with WM 1505 E. Am J Pathol 1977; 88: 193.

3. Dekaban GA, Rice GPA. Retroviruses in multiple sclerosis: II. Failure of gene amplification techniques to detect viral sequences unique to the disease. Neurology 1990; 40: 12541258.

4. Power C, Weinshenker BG, Dekaban GA, Kaufmann JCE, Rice GPA. Pathological and molecular biological features of a myelopathy associated with HTLV-I infection. Can J Neurol Sci 1991; 18: 352-355.

5. Loche M, Mach B. Identification of HIV-infected seronegative individuals by a direct diagnostic test based on hybridization to amplified DNA. Lancet 1988; ii: 418-421.

6. D'Auriol L, Vernant JC, Ouka M, et al. Diagnosis of HTLV-1 infected seronegative neurological patients by polymerase chain reaction amplification in Martinique. Nouv Rev Fr Hematol 1990; 32: 113-116.

7. Kwok S, Higuchi R. Avoiding false positives with PCR. Nature 1989; 239: 237-238.

8. Seiki M, Seisuke H, Hirayama Y, Yoshida M. Human T-cell leukemia virus: complete nucleotide sequence of the provirus GENOME integrated in leukemia cell DNA. Proc Nat Acad Sci 1983; 80: 3618-3622.

9. Shimotohno K, Takahashi Y, Shimizu N, et al. Complete nucleotide sequence of an infectious clone of human T-cell leukemia virus 
type II: an open reading frame for the protease gene. Proc Natl Acad Sci USA 1985; 82: 3101-3105.

10. Koprowski H, DeFreitas EC, Harper ME, Sandberg-Wolheim M, Sheremata WA, et al. Multiple sclerosis and human T-cell lymphotropic retroviruses. Nature 1985; 318: 154.

11. Ehrlich GD, Glaser JB, Bryzgomia V, et al. Multiple sclerosis, retroviruses, and PTC (Review). Neurology 1991; 41(3): 335343.

12. Jocher R, Rethwilm A, Kappos L, et al. Search for retroviral sequences in peripheral blood mononuclear cells and brain tissue of multiple sclerosis patients. J Neurol 1990; 237(6): 352-355.
13. Oskenberg JR, Mantegazza R, Sakai K, et al. HTLV-I sequences are not detected in peripheral blood genomic DNA or in brain cDNA of multiple sclerosis patients. Ann Neurol 1990; 28(4): 574-577.

14. Chen ISY, Haislip AM, Myers LW, et al. Failure to detect human Tcell leukemia virus-related sequences in multiple sclerosis blood. Arch Neurol 1990; 47; 10: 1064-1065.

15. Perl A, Nagy K, Pazmany T, et al. No evidence for human T-cell leukemia virus type I or human T-cell leukemia virus iype II infection in patients with multiple sclerosis. Arch Neurol 1990; 47(10): $1061-1063$. 